\title{
A propósito de una amistad. Encuentros y divergencias entre Rubén Darío y Rufino Blanco-Fombona
}

\author{
Carmen SosA GIL \\ Universidad Complutense de Madrid
}

\section{RESUMEN}

Este artículo es una aproximación a las relaciones literarias y amistosas entre Rubén Darío y Rufino Blanco-Fombona, a partir de la correspondencia suscrita entre ambos escritores. Se pretende resaltar la particularidad de afectos por sobre la diferencia de personalidades.

Palabras clave: Modernismo, amistad, correspondencia, temperamentos, Rufino Blanco Fombona, Rubén Darío.

\section{About a Friendship. Meetings and Differences between Rubén Darío and Rufino Blanco-Fombona}

\begin{abstract}
This article is an introduction to literary and friendly relations between Rubén Darío and Rufino Blanco-Fombona, from correspondence signed between the two writers. It aims to highlight the particular affection for the difference of personalities.
\end{abstract}

Keywords: Modernism, friendship, correspondence, temperaments, Rufino Blanco-Fombona, Rubén Darío.

Artistas de las más diversas tendencias, escritores de todo pelaje, críticos de arte, políticos de ideologías opuestas, todos o casi todos, desfilan por las páginas y por la vida del poeta Rubén Darío a lo largo de su azarosa vida, especialmente durante los años de su permanencia en Argentina y en España. Hay para ellos un recuerdo, una frase, un gesto de cariño o agradecimiento, o una simple palabra de cortesía. Y es que para este hombre, más tímido y reservado de lo que pudiera deducirse de sus biografías, la amistad y las buenas relaciones ocuparon una porción vital de su existencia.

Dentro de este crecido número de amistades hay una que resulta interesante resaltar, no tanto por la cercanía a los afectos de Darío sino por la peculiaridad de su vida y de su obra, por la claridad que puede ofrecernos a la hora de contrastar dos personalidades tan disímiles y, a la vez, tan cercanas en ocupaciones, oficios e 
intereses. Me refiero a la relación literaria y amistosa entablada con el escritor venezolano Rufino Blanco Fombona (1874-1944). ${ }^{1}$

Podría decirse que, desde sus orígenes, la trayectoria de ambos escritores es diferente. $\mathrm{Y}$ aunque son personalidades totalmente opuestas, en su vida y su obra tienen en común mucho más que la vocación literaria, las tendencias modernistas dentro de la literatura o el oficio diplomático.

La vida e inquietudes literarias del Continente, así como las tareas diplomáticas que ambos asumieron en su vida adulta -matizadas por la búsqueda de una mejor posición socio-económica en el primer caso y por las consecuencias de sus incursiones políticas en el segundo- van a permitir que posteriormente sus caminos se encuentren.

Aunque nace en una familia tradicional, por las condiciones peculiares de sus padres, es bien sabido que la niñez y adolescencia de Rubén Darío se desarrolló bajo el cuidado de su tía Bernarda y estuvo marcada por la precariedad y la pobreza. Darío, desde muy joven, salió de su entorno natal por razones perentorias: buscando mejores condiciones económicas y un espacio que le permitiera desarrollar sus inclinaciones literarias.

Blanco-Fombona nació y creció en el seno de una familia acaudalada, de rancio linaje, que contaba entre sus ancestros próceres de la Independencia, juristas y escritores notables. Su salida del suelo venezolano tuvo una relación directa con su participación en la vida política, diplomática y cultural de Venezuela compromiso que, por lo demás, heredó de sus padres y que asumió con la clara conciencia del deber moral para con la patria.

Sus protestas contra el régimen dictatorial de Juan Vicente Gómez le valieron un largo destierro de veintiséis años, período que marcará gran parte de su vida y su obra. Se mantuvo siempre atento e informado sobre la situación del país, y siempre dispuesto a participar activamente, desde el exilio, en cualquier intento por lograr una salida democrática. En Dos años y medio de inquietud (1942), su último diario, a propósito de estas luchas, encontramos frases como "¡Cómo me duele el dolor de la tierruca!” Y líneas más adelante: “iQué luchas! ¡Qué esperanzas! ¡Qué decepciones! Conspirar durante años y años por derrocar al Traidor"; y también, "No; no somos una casta nacida para la esclavitud." (Blanco-Fombona, 2004: 205).

Asimismo sus temperamentos marcan diferencias entre ambos literatos. Rubén Darío era de un carácter apacible, tímido e introvertido. Uno de sus biógrafos hace un comentario que puede aplicarse a muchas situaciones de su vida: "por su timidez

${ }^{1}$ Rufino Blanco Fombona (Caracas, 1874-Buenos Aires, 1944). Editor, poeta, narrador, historiador y diplomático, brillante y polémico a la vez, es figura destacada de la poesía modernista venezolana. Considerado por la crítica una de las personalidades hispanoamericanas más atractivas de la primera mitad del siglo XX, es también una de las menos comprendidas. Tiene entre sus mejores logros el haber intentado restituir la dimensión literaria y política de la obra de Simón Bolívar, sobre quien escribió extensos ensayos y editó gran parte de sus cartas y discursos. 
invencible, por su respeto a las alcurnias y por su escaso dominio de la palabra hablada, Darío se contenta con escuchar y admirar, bien que cuando tiene que decir algo lo hace con discreción" (Torres: 287). El mismo poeta menciona en sus recuerdos, "una fatal timidez que todavía me dura" (Darío, 2007: 65). Y en una carta a uno de sus amigos, reconoce la naturaleza de su "carácter" y sus "nervios".

Blanco-Fombona, por el contrario, poseía un temperamento recio y cambiante, de rápidas y extremosas pasiones, que desplegaba fuerza y que, debido a sus cambios de humor, en muchas ocasiones resultaba contradictorio. Al respecto el mismo escritor expresará en su Diario, "Debe de haber una contradicción fundamental en mi naturaleza, que se traduce en antinomias personales" (Blanco-Fombona, 2004: 180). Pero esos excesos de su temperamento no se desatan sólo en reacciones de cólera, como se ha dicho tanto de él, se descubren en pequeñeces que lo conmueven en uno u otro sentido, como también comentará en su Diario: "Soy sensible al más mísero elogio, lo propio que al reproche más ruin.” (Blanco-Fombona, 2004: 105).

Pero no olvidemos que tanto el poeta nicaragüense como el escritor venezolano son hijos de su tiempo; sus vidas y obras no pueden desligarse de sus contextos históricos y del panorama cultural y literario hispanoamericano. En el caso de Darío, las tareas diplomáticas que cumple al servicio de Nicaragua le vinculan de una manera indirecta al ambiente político y en algunas ocasiones le comprometen en este campo más de lo que el mismo Darío quisiera. En Blanco Fombona, como se ha dicho, sus incursiones en la vida política venezolana tienen un tinte de responsabilidad moral hacia la patria que aún en el destierro no posterga.

Por otra parte, ambos escritores tuvieron conciencia del momento cultural y literario que les tocó vivir. La estética modernista, a la que ambos se afiliaron, rindió culto preponderante a la personalidad, a la individualidad, por encima de la comunidad artística. El concepto plural del modernismo incluyó los matices particulares y las inflexiones personales de cada uno de los artistas que lo conformaron y es justamente esa diversidad de expresiones la que "permite abarcar este fenómeno estético como movimiento" (Castagnino: 12), y lo que le confiere un lenguaje y un estilo propios.

Aquella manera de ubicarse socialmente y de hacerse oír, que resultó tan novedosa en artistas como Baudelaire a mediados del siglo XIX, marcaría la figura del nuevo dandi, cuyo estilo cobró fuerza tanto en la intelectualidad europea como en la de América Latina en los finales decimonónicos. Ser dandi no sólo es "urbanizarse: seguir un manual de conducta y modificarlo a su antojo con talento y distinción." (Darrigrandi: 146). Es también tener unos gestos llamativos, una manera de vestir o un comportamiento provocador y agresivo que, al mismo tiempo que proyecta la imagen del artista varón, le distancia del modelo del hombre productivo de la sociedad capitalista de finales de siglo. Porque la pose, entendida como expresión

${ }^{2}$ Carta $N^{\circ} 404$, fechada en Madrid a 12 de enero de 1909. Se encuentra en el Libro de copias 2, del Archivo Rubén Darío de la Universidad Complutense de Madrid. 
cultural, resultó "una forma de relación política de la intelectualidad que posa y condena la simulación al mismo tiempo" (Montaldo: 129).

Con la instauración de la nueva economía de mercado la situación del artista cambió considerablemente. De ser uno de los protagonistas de la escena social, el artista y el poeta en particular, está forzado a desaparecer; no hay sitio para él en una sociedad en la que el arte es una mercancía, un producto más. "Ser poeta pasó a constituir una vergüenza" y su imagen fue la del vagabundo o desequilibrado, incapaz e improductivo que se encuentra ante un público ignorante y hostil que no le escucha y mucho menos retribuye su canto. Al respecto Ángel Rama afirma que,

Si no se comienza por establecer esta situación de rechazo de la creación artística por la estructura socioeconómica creada, será difícil entender a los poetas del período modernista. Persistirá entonces esa soterrada convicción de que ellos, por libre y suicida vocación, decidieron rehusarse al servicio de la comunidad y encerrarse en bloqueadas torres de marfil. (Rama, 1985: 59-60) ${ }^{3}$

Ya sabemos que la realidad fue otra; que el poeta tuvo que acomodarse a esta nueva forma de vida y debió negociar su producción a cambio de los recursos necesarios para vivir y continuar creando. Para el mismo Rama, "esta problemática explica que el poeta y la poesía hayan devenido, desde el romanticismo, pero alcanzado su ápice en el modernismo, el tema central de la creación." Es verdad que ante la hostilidad y el desinterés dominantes el poeta se aísla o se aparta, pero con la intención de resguardar su arte. Es decir que, "En esta distancia, en ese cotejo con la sociedad, el poeta decanta su valor propio, reconoce su naturaleza y se transforma en autotema de su creación" (Rama, 1985: 62 y 63).

También Darío participó, a su modo, de estas posturas de la cultura letrada finisecular que se arrogaron muchos intelectuales modernistas, y aún cuando siempre soñó sus circunstancias vitales y tuvo la conciencia y la voluntad de «ser diferente», como respuesta al medio social, vivió una vida apasionada e itinerante, muy "acorde con la sensibilidad cultural de la época y con el afán universal y cosmopolita del artista romántico y posromántico" (Cabrera: 23).

Darío no sólo fue un rebelde en el campo literario, que se atrevió a rechazar lo que consideraba caduco respecto a la poesía, y que muchas veces se mantuvo al margen de un mundo incapaz de valorar su arte, "fue también un provocador de actitud muchas veces belicosa y agudamente rebelde que se enfrentaba a todo aquello que le pareciera conservador, tradicionalista, dogmático o infructuosamente pedagógico" (Cabrera: 26). Sin embargo, aunque su figura es representativa del artista modernista y en algunos casos ejerció una crítica mordaz, Darío - por su temperamento- prefirió

${ }^{3}$ También el artículo de Kelly Comfort, "Masculinidad rechazada: el artista recluido y no productivo en Darío y Silva”, en la obra citada de Anna Peluffo e Ignacio Sánchez. 
mantenerse en un segundo plano antes que promocionarse en el medio social, especialmente el europeo, como sí lo hicieron otros escritores hispanoamericanos. ${ }^{4}$

En cuanto a Blanco-Fombona, aunque sus expresiones pasionales e impulsivas tengan bastante que ver con su genio, también encontramos en él mucho de esa postura cultural del período que algunos intelectuales ejercieron con osadía, y que, obviamente, se vertió al campo literario. En la mayoría de los casos, se sirvieron del libelo como medio de difusión de las ideas o posturas y "las polémicas sirvieron como ejercicio de la injuria, proliferaron los folletos calumniosos y anónimos, se escribieron mensajes destinados a destruir verbalmente al enemigo". Cuando BlancoFombona fue objeto de esos ataques, no dejó de responder en igualdad de términos, pues tenía, "una eficacia literaria, un ingenio y una acidez que centuplican la fuerza demoledora de los agravios" (Rama, 2004: XXXIV y XXXV). Sus obras, en especial sus cartas y el Diario recogen diversas muestras de estos exabruptos, que alcanzaron a escritores y amigos y al mismo Rubén Darío.

Por otra parte, la exaltación de la personalidad y de la vida del artista (propia de románticos y modernistas), se equiparó en importancia a su obra literaria, de ahí que muchos de los escritores de la época se esforzaran por concebir y construir una imagen de sí mismos que lograra ser apreciada o admirada, pues según opinión de Ángel Rama, "la norma del artista nacido en el simbolismo consistiría en «representar», en forjar su vida de conformidad con un determinado proyecto" (Rama, 2004: XX), para hacer de ella un espectáculo, una obra de arte.

Esa originalidad personal, concebida como la máxima expresión del arte puede hacernos entender, "la devoción de Blanco Fombona por su obra poética, pues en ella era él, su plena subjetividad, la que estaba presente y hablaba;" puede explicarnos, asimismo, el que "durante treinta años haya mantenido un «diario íntimo» dejándonos en esas anotaciones lo mejor de su obra literaria" (Rama, 2004: XII). Lo confirma el mismo escritor al decir que lo que más le atrae de un libro es el autor y por ello "no leo libros tontos o vulgares; [...] La lectura que prefiero es la de un Diario íntimo; o de unas Memorias, sobre todo si no son políticas ni de algún militar" (Blanco Fombona, 2004: 183).

Puede también mostrarnos por qué Darío prefirió las memorias al diario. Posiblemente el género le inspirara cierta desconfianza, como a muchos otros escritores peninsulares e hispanoamericanos (Rama, 2004: XIV). La biografía, en cambio, le permitió elegir cuáles de sus recuerdos publicar. De ahí que su relato autobiográfico resulte reservado y fragmentario, menos espontáneo de lo que pudiera pensarse. Quizá también por evitar indiscreciones, "Rubén Darío se cuidó siempre de no regalar o vender su intimidad, pues ésta significaba la parte o el elemento más sagrado y privativo de su persona" (Cabrera: 21). Dada su personalidad tímida y circunspecta, no parece ser de las personas que registran todas sus vivencias en un diario. Además él, siempre dispuesto a complacer y sobre todo, a dejarse seducir por

\footnotetext{
${ }^{4}$ Véase “La exposición Rubén Darío” en Juana Martínez y Rocío Oviedo, p.24.
} 
la vida y sus goces, "estuvo enajenado por otras pasiones que estaban en el tiempo, aunque apenas le correspondieran: Darío, más que vivir, se deja vivir" (Cabrera: 26).

Aunque hemos comentado algunas facetas de la vida ambos escritores, nos acercaremos a la relación de amistad entablada entre ellos. A través de los documentos del Archivo Rubén Dario de la Universidad Complutense de Madrid, se puede rastrear parte del intercambio epistolar entre Darío y Blanco-Fombona para darnos una idea más aproximada de esta relación. El Archivo Rubén Dario ${ }^{5}$ guarda catorce documentos (nueve cartas y cinco tarjetas) de Blanco-Fombona a Darío, mientras que en la dirección contraria, de Darío al escritor venezolano, sólo posee tres cartas. ${ }^{6}$

Esta correspondencia se establece entre 1902 y 1911, de acuerdo a las fechas que aportan los referidos documentos, y aunque no es muy extensa, el período que abarca habla de una relación más que temporal o circunstancial entre ambos.

El contenido de las cartas y el mayor número de ellas dirigidas por BlancoFombona a Darío hace pensar, a primera vista, en un deseo mayor de comunicación y por tanto de amistad del venezolano hacia el nicaragüense, hecho que se comprende dada la personalidad extrovertida del primero. Pero también se puede contemplar la posibilidad de alguna carta más de Darío a Blanco-Fombona (todavía desconocida), en respuesta a alguna más de todas esas misivas que conserva el Archivo, si se tiene en cuenta la costumbre del poeta de contestar con regularidad su correspondencia.

La fecha más probable del primer encuentro de ambos escritores es el año 1901 en París, según recuerda el mismo Blanco-Fombona: “¿Mis relaciones con Rubén? Estuvimos muy unidos desde principios de 1901" (Blanco Fombona, 1929: 147) . En su texto El modernismo y los poetas modernistas, el escritor venezolano habla de su relación con el poeta nicaragüense y deja sentado que, a pesar de las diferencias temperamentales e ideológicas, o de la distinta forma de afrontar la vida, la amistad entre ellos fue "muy estrecha y muy cordial" (Blanco Fombona, 1929: 147 y 155).

En sus recuerdos, considera a Darío,"el mayor poeta que ha producido la América hispánica"; "uno de los mayores líricos contemporáneos", una mente brillante que "iluminaba el camino de nuestra generación", en fin, lo reconoce como "un maestro." Al evocar su figura dice de Rubén que, "era tolerante", bueno y discreto, "lo comprendía, lo disculpaba y lo admiraba todo" (Blanco Fombona, 1929: 147-148 y Ss.).

De igual modo, a lo largo del intercambio epistolar, se puede constatar el aprecio de Blanco-Fombona por la persona y la obra del poeta nicaragüense. En las cartas encontramos expresiones como, "créame siempre leal" (ARD, 1653), "tiene un talento muy bello y un alma blanca... Yo lo quiero mucho. Lo abrazo, querido Rubén"

${ }^{5}$ En adelante se identificará el Archivo Rubén Darío con las siglas ARD, y los documentos citados del mismo con su correspondiente numeración, precedida de las siglas nombradas.

${ }^{6}$ Estas tres cartas son la $\mathrm{N}^{\circ} 168, \mathrm{~N}^{\mathrm{o}} 188$ y No 203 , registradas en el Libro $2^{\circ}$ de copias. Las cartas de Blanco-Fombona a Darío están en las Carpeta $\mathrm{N}^{\mathrm{o}} 31$ y N $\mathrm{N}^{\mathrm{7}} 75$, en los apartados de las mismas dedicados a Venezuela. 
(ARD, 1659); al anunciarle un próximo encuentro en París, le dice que, "iré a abrazarlo a su casita" (ARD, 1658). En la última carta de Blanco-Fombona, registrada en el ARD y fechada en París el 1 de marzo de 1911, carta seguramente relacionada con el suceso entre ambos escritores a causa de Mundial y los Hnos. Guido, BlancoFombona se disculpa pues "creo haberle importunado en mi última visita" y se pone a su disposición (ARD, 4664).

También en las cartas que se conservan en la Biblioteca Nacional de Chile ${ }^{7}$, que forman parte de esta correspondencia, el venezolano dejará sentados, tanto su afecto como su valoración de la obra del poeta centroamericano. En frases como, "La autoridad entre la gente de pluma, y el prestigio en el gran público, que tiene U. en España no lo tiene igual ningún otro" (BNCh, 8-6-1904). En esta misma carta dice acerca del prólogo que Rubén acaba de escribir para su poemario Pequeña ópera lírica, que es "tan hermoso como fraternal". Son constantes las demostraciones de aprecio y cercanía: "créame siempre su mejor amigo" (BNCh, 3-8-1907), "una, dos, tres veces lo abrazo" (BNCh, 8-6-1904); o una expresión tan cercana y reveladora de afecto como ésta: "Hoy más que nunca lo quiero porque lo admiro, y lo admiro porque lo comprendo." (BNCh, 6-2-1906). Asimismo encontramos en el intercambio epistolar asuntos literarios variados, comentarios a las obras escritas por ellos o por otros, así como el interés por las últimas publicaciones hechas en Europa o por la figura de los escritores más relevantes de la época.

Si bien es cierto que muchas de las expresiones que aparecen en éstos como en otros epistolarios son fórmulas de cortesía propias de la época, se percibe en muchas de ellas un tono efusivo que rebasa la simple corrección y que quizá pueda explicarse, al mimo tiempo que desde el afecto sincero, a partir de esa camaradería o compañerismo privativo de los círculos masculinos políticos, culturales y literarios de finales del siglo XIX.

En todo caso, Blanco-Fombona dejó constancia de su amistad, por encima del malentendido que hubo entre ellos ${ }^{8}$ (asunto sobre el que se excusó en el texto citado líneas atrás, como también hicieron, respecto a Darío, otros escritores como Francisco Contreras o José $\mathrm{M}^{\mathrm{a}}$. Vargas Vila.) ${ }^{9}$ Se ha propagado con insistencia la ruptura entre ambos escritores, y también se ha difundido la aceptación de su error por parte del intelectual venezolano. Quizá, en aras de la amistad, sea necesario acentuar el justo y sincero reconocimiento que éste último hizo de Darío, tanto de su figura como de su obra poética.

${ }^{7}$ La correspondencia que conserva la Biblioteca Nacional de Chile entre ambos poetas, aparecerá aquí con las siglas BNCh y la fecha de cada misiva. Puede verse parte de esas cartas en Alberto Ghiraldo, El Archivo de Rubén Darío, Buenos Aires, Losada, 1943.

${ }^{8}$ El incidente entre Blanco-Fombona y Darío a causa de Mundial y los Hnos. Guido, que puede verse en E. Torres pp. 728-730, es probablemente mayo o junio de 1911. También en la obra de Blanco-Fombona, El modernismo y los poetas modernistas, pp. 147 y ss.

${ }^{9}$ Véase "La exposición Rubén Darío" en Juana Martínez y Rocío Oviedo, p. 23. 
Es posible que, volver aquí sobre el conocido reclamo del venezolano a Darío a causa de su famosa Salutación al Águila, sea llover sobre mojado, pero sólo mencionaré dicho suceso para enfatizar ese otro aspecto del que se viene hablando. A pesar de su disgusto, Blanco-Fombona es capaz de reconocer quién ha sido y sigue siendo Rubén Darío: "Usted nuestra gloria, la más alta voz", "divino poeta". Así mismo, siente que puede desahogar su reproche debido al implícito afecto que media entre ambos, "el dolor que me ha producido... usted si lo comprende porque usted si me conoce"; y para despedirse dice, reconociendo su tono áspero, "No me resta sino pedirle perdón por esta carta antipática y refistolera. Escribir cartas es cosa que nunca aprenderé" (BNCh, 3-8-1907).

Demás está comentar en la carta de respuesta de Darío, tan comentada (BNCh, 188-1907), el tono conciliador y esperanzado, no exento de idealismo, con el cual escribió su Salutación y desde el que soñaba la concordia entre los pueblos de América. Claro, esa concordia era un sueño compartido por ambos escritores que esperaban mucho más de lo que se dio en la Conferencia Panamericana de Río de Janeiro.

Es admisible entender la reacción que causó el poema de Darío en BlancoFombona. Conocido por sus ideas hispanistas y su postura antiimperialista casi monolítica y cuya vida, al mismo tiempo, está signada por "un temple de sinceridad" (Sanoja Hernández: XVII ), es hasta cierto punto lógico que no perdone en Darío lo que para él debió ser una doblez o deslealtad en lugar de una lección de raza; respuesta compartida por otros escritores y políticos de América que lo consideraron entonces una traición a la causa común de lo hispano y contrario a lo expresado por Darío en cantos anteriores. ${ }^{10}$

Durante mucho tiempo la figura de Darío como intelectual de combate estuvo subordinada a "la imagen del inspirado bohemio e improvisador alcoholizado creada por la mitología popular" (Arellano y Kraudy: 8). Sin obviar esas debilidades que rodearon su vida y que en momentos empañaron sus acciones, también se cuentan entre sus preocupaciones constantes su liberalismo político y sus luchas a favor de la unión de los pueblos centroamericanos. Pero es de notar que hay un cambio en sus planteamientos tanto poéticos como socio-políticos. Aun cuando la paz sigue siendo un anhelo, su consecución es un sueño casi imposible por las dificultades internas de los pueblos americanos, y Darío que asume el propósito panamericano de la Conferencia, invita -quizá desde un idealismo- a contar con la presencia de los Estados Unidos en la búsqueda de su progreso. El Darío que en la oda $A$ Roosevelt descubre por un lado sus sentimientos americanistas y por el otro, su visión del mandatario como sinónimo de "invasor" "potente" (Darío, 1994: 118), en la Salutación pedirá al Águila, "Tráenos los secretos de las labores" y que ambos -Águila y Cóndor- "puedan juntarse en concordia" (Darío, 1994: 153).

${ }^{10}$ Véase, el comentario a la carta de Blanco-Fombona en Alberto Ghiraldo, p.141 y en Pedro Salinas, pp. 242 y ss. 
Con respecto a aquella recriminación de Blanco-Fombona, años después escribirá Darío a su amigo Fabio Fiallo, "Te remito un artículo que he publicado hoy en el diario de la élite intelectual de París. Ahora no dirá Blanco-Fombona que yo adulo al Águila Norteamericana" ${ }^{11}$ Al respecto comenta Jorge Arellano la repercusión que tuvo dicho artículo en las palabras del dominicano Federico Henríquez Carvajal, quien ve en el mismo una petición de respeto hacia Nicaragua por parte del Presidente de los Estados Unidos, así como una justa defensa de los pueblos latinoamericanos (Arellano y Kraudy: 33 y 34).

Si bien la imagen de Darío que proyectan los recuerdos de Blanco-Fombona -en la obra ya citada- resulta para algunos "doméstica" y "lamentable" (Castagnino: 52), es posible verle desde otra perspectiva. Más allá de los arrebatos verbales y del extremoso temperamento del venezolano hay una justa reivindicación del Rubén Darío de carne y hueso que conocieron y sufrieron -¿por qué no?- sus contemporáneos.

Un Darío real, generoso, cercano y amistoso, pero también asustadizo, retraído e incapaz, muchas veces, de sustraerse a sus pasiones; con todas las menudencias y genialidades que rodearon su vida pero que, precisamente por esa carga de 'humanidad', pueden darle su merecido lugar en la poesía y en las letras hispanoamericanas. El mismo Blanco-Fombona confirma estas apreciaciones cuando dice que es preciso hablar de Rubén Darío "como de un hombre", puesto que, "era de carne y hueso como nosotros" (Blanco Fombona, 1929: 165).

En estos comentarios se reconoce una sinceridad descarnada y un tanto mordaz que despoja al poeta de apologías, endiosamientos y frases hechas y lo muestra como una persona en toda la extensión de la palabra. El resultado es una imagen quizá demasiado frágil y carnal para el gusto de algunos y para el común estereotipo de la época. Un Darío humano, sediento de amor y de deseos vitales que transitó por las calles del mundo, que escribió poemas en servilletas, y que estuvo siempre dispuesto a compartir bohemias y tristezas.

Quizá ese Darío "en pantuflas" nos guste más que el magnífico "artista inmortal, magnífico" (Castagnino: 52), ahora que la literatura, superadas tantas apologías y peanas, en sus incursiones 'post-' (postvanguardistas, postrománticas y postmodernistas) escudriña epistolarios, autobiografías y diarios, en busca de la verdad desnuda, de la vida sencilla y sin retoques de los protagonistas de esas páginas.

${ }^{11}$ Carta a Fabio Fiallo, el 27 de marzo de 1910 desde París. Esta carta aparece en el libro de José Jirón Terán, Cartas desconocidas de Rubén Darío (1882-1916), Managua, Academia nicaragüense de la Lengua, 2000, p. 303, con el número 168. El artículo en cuestión apareció en el París Journal, el 27 de mayo de 1910. 


\section{BIBLIOGRAFÍA}

BLANCO-FOMBONA, Rufino.

1929 El modernismo y los poetas modernistas. Madrid: Mundo Latino.

2004 Diarios de mi vida. Una selección. Caracas: Monte Ávila Latinoamericana.

BLANCOFOMBONA, Maguy.

2009 "Tras los manuscritos de Rufino Blanco-Fombona. La creación del Archivo", Escritural, nº 1, Marzo.

http:www.mshs.univ-poitiers.fr/crla/contenidos/ESCRITURAL/ES...

BiBLIOTECA NACIONAL DE CHILE.

Correspondencia: http://www.bncatálogo

CABRERA CARTAYA, Iván.

2007 "Prólogo", en Rubén Darío, La vida de Rubén Darío escrita por él mismo e historia de mis libros. La Laguna: Artemisa.

CASTAgnino, Raúl.

1967 Imágenes Modernistas. Buenos Aires: Nova.

COMFORT, Kelly.

2010 "Masculinidad rechazada: el artista recluido y no productivo en Darío y Silva", en Anna Peluffo e Ignacio Sánchez. Entre hombres: masculinidades del siglo XIX en América Latina. Madrid: Iberoamericana-Vervuert.

DARÍO, Rubén.

1994 Antología. Ed. de Carmen Ruiz Barrionuevo. Madrid: Espasa Calpe.

2007 La vida de Rubén Dario escrita por él mismo e historia de mis libros. Pról. de Iván Cabrera Cartaya. La Laguna: Artemisa.

2010 Escritos políticos. Sel., estudios y notas de Jorge Eduardo Arellano y DARRIGRANDI, Claudia. Pablo Kraudy Medina. Managua: Banco Central de Nicaragua.

2009 "De 'Fulano' a dandi: escenarios, performance y masculinidad en Pot Pourri silbidos de un vago) de Eugenio Cambaceres", en Anna Peluffo e Ignacio Sánchez. Entre hombres: masculinidades del siglo XIX en América Latina. Madrid: Iberoamericana-Vervuert.

GHIRALDO, Alberto.

1943 El Archivo de Rubén Darío. Buenos Aires: Losada.

MARTínez GóMEZ, Juana y OVIEDO PÉREZ DE TUDELA, Rocío.

2008 Rubén Dario. Las huellas del poeta. Madrid: Biblioteca Complutense-Ollero y Ramos.

MONTALDO, Graciela.

2009 "Hombres de la multitud y hombres de genio en el fin-de-siècle", en Anna Peluffo e Ignacio Sánchez. Entre hombres: masculinidades del siglo XIX en América Latina. Madrid: Iberoamericana-Vervuert. 
RAMA, Ángel.

2004 "Prólogo", en Rufino Blanco-Fombona. Diarios de mi vida. Una selección, Caracas: Monte Ávila Latinoamericana.

1985 Rubén Dario y el Modernismo. Caracas: Alfadil. (S. A.)

2011 "Rufino Blanco-Fombona" http://www.biografíasyvidas.com/biografía/blanco_fombona.htm

SALINAS, Pedro. [Consulta: 12-04-2011].

1975 La poesía de Rubén Dario. Barcelona: Seix Barral.

SANOJA HERNÁNDEZ, Jesús.

1981 "Blanco Fombona y el país sin memoria", en Rufino Blanco Fombona. Ensayos históricos. Caracas: Biblioteca Ayacucho.

TORRES, Edelberto.

1982 La dramática vida de Rubén Darío. Costa Rica: Editorial Universitaria Centroamericana.

VILLACASTÍN, Rosario.

1987 Catálogo del Seminario Archivo Rubén Darío. Madrid: Universidad Complutense. 